\title{
Multisystemic Therapy and Functional Family Therapy Compared on their Effectiveness Using the Propensity Score Method
}

\author{
Hester V. Eeren ${ }^{1,2} \cdot$ Lucas M. A. Goossens $^{3} \cdot$ Ron H. J. Scholte ${ }^{1,4}$ • Jan J. V. Busschbach ${ }^{1,2}$ - Rachel E. A. van der Rijken ${ }^{1}$
}

Published online: 9 January 2018

(C) The Author(s) 2018. This article is an open access publication

\begin{abstract}
Multisystemic Therapy (MST) and Functional Family Therapy (FFT) have overlapping target populations and treatment goals. In this study, these interventions were compared on their effectiveness using a quasi-experimental design. Between October, 2009 and June, 2014, outcome data were collected from 697 adolescents (mean age 15.3 (SD 1.48), 61.9\% male) assigned to either MST or FFT (422 MST; 275 FFT). Data were gathered during Routine Outcome Monitoring. The primary outcome was externalizing problem behavior (Child Behavior Checklist and Youth Self Report). Secondary outcomes were the proportion of adolescents living at home, engaged in school or work, and who lacked police contact during treatment. Because of the nonrandom assignment, a propensity score method was used to control for observed pre-treatment differences. Because the riskneed-responsivity (RNR) model guided treatment assignment, effectiveness was also estimated in youth with and without a court order as an indicator of their risk level. Looking at the whole sample, no difference in effect was found with regard to externalizing problems. For adolescents without a court order, effects on externalizing problems were larger after MST. Because many more adolescents with a court order were assigned to MST compared to FFT, the propensity score method could not balance the treatment groups in this subsample. In conclusion, few differences between MST and FFT were found. In line with the RNR model, higher risk adolescents were assigned to the more intensive treatment, namely MST. In the group with lower risk adolescents, this more intensive treatment was more effective in reducing externalizing problems.
\end{abstract}

Keywords Propensity score $\cdot$ Comparative effectiveness research $\cdot$ Adolescent $\cdot$ Quasi-experimental study $\cdot$ Behavioral problems

Multisystemic Therapy (MST) and Functional Family Therapy (FFT) both originated from the United States (US). Their proven effectiveness in reducing adolescents' antisocial behavior and delinquency has led to the worldwide dissemination of these interventions. Both MST and FFT are aimed at

Electronic supplementary material The online version of this article (https://doi.org/10.1007/s10802-017-0392-4) contains supplementary material, which is available to authorized users.

Hester V. Eeren

h.vaneeren.1@erasmusmc.nl

Lucas M. A. Goossens

goossens@eshpm.eur.nl

Ron H. J. Scholte

r.scholte@pwo.ru.nl

Jan J. V. Busschbach

j.vanbusschbach@erasmusmc.nl

Rachel E. A. van der Rijken

rachel.van.der.rijken@ deviersprong.nl reducing the behavioral problems of 12-18 year old adolescents by intervening in the youth's family and environmental system. Functional Family Therapy has an integrated theoretical base in which behavioral techniques, system perspectives, and cognitive theory are combined while remaining informed

1 Viersprong Institute for Studies on Personality Disorders (VISPD), Halsteren, The Netherlands

2 Department of Psychiatry, Section Medical Psychology and Psychotherapy, Erasmus Medical Center, Rotterdam, The Netherlands

3 Erasmus School of Health Policy and Management, Erasmus University Rotterdam, Rotterdam, The Netherlands

4 Behavioural Science Institute, Radboud University Nijmegen, Nijmegen, The Netherlands 
by intrapsychic perspectives (Breuk et al. 2006; Sexton and Alexander 2003). Antisocial behavior is thought to be mediated and embedded in a complex sequence of relations between the adolescent and his or her family members (Sexton and Alexander 2003). Therefore, FFT is specifically aimed at improving family communication and supportiveness while decreasing negativity and dysfunctional behavioral patterns (Blueprints for healthy youth development 2015). The therapy mainly consists of direct contact with family members, but may be coupled with support system services, such as school or work. Research has shown that FFT is effective in reducing (delinquent) behavioral problems, recidivism, and substance abuse, and that it guides family members in improving their family situation (Alexander and Sexton 2002; Sexton and Alexander 2000; Sexton and Turner 2010).

Caregivers are also seen as the most important link in the treatment process of MST, but MST also actively involves all other systems surrounding the youth, such as friends, schools, and neighborhoods (Henggeler et al. 2009). This approach is founded in the social-ecological theory of Bronfenbrenner (1979), in which it is thought that antisocial behavior is multi-determined by the different social systems in which an individual acts. By intervening in and with these social systems, risk factors are reduced and a youth's social environment is changed such that it stimulates prosocial activities instead of antisocial behavior (Henggeler et al. 2009). Multisystemic Therapy is more intensive than FFT, because a therapist visits the family at home and is available to the family round-the-clock. Research has shown that MST effectively reduces behavioral problems and delinquency, recidivism, substance abuse, out-of-home placement, family problems, and involvement with deviant peers (Henggeler 2011; van der Stouwe et al. 2014).

The effectiveness of both MST and FFT is well-established compared to regular treatment, such as individual treatment, family-based interventions, or parenting counseling (Asscher et al. 2013; Sundell et al. 2008). Multisystemic Therapy and FFT clearly show overlap in their target populations and treatment goals (e.g., Chorpita et al. 2011; Henggeler 2011; Sexton and Turner 2010). Given this overlap, the question arises what intervention works best for whom. However, little is known about their relative effectiveness (i.e., whether one intervention outperforms the other).

A recent study by Baglivio et al. (2014) compared the effectiveness of MST and FFT in juvenile practice in the US. In this study, youth receiving MST or FFT had been referred by probation officers from the juvenile justice department. Results showed little significant difference in the effectiveness of the two interventions. However, low-risk youth receiving FFT committed fewer offenses during treatment than low-risk youth receiving MST. Because referral practices and treatment populations differ between countries (Asscher et al. 2013; Sundell et al. 2008), the relative effectiveness of MST and
FFT is unknown outside the US. In the Netherlands, youth are referred to MST or FFT by various referral agencies, including the Child Protection Council, juvenile judges, local referral institutions, and primary health care providers. Compared to allocation procedures in the US, in the Netherlands youth are less often referred to MST or FFT by a judicial agency. This could influence the target population as well as treatment effects. We, therefore, studied the relative effectiveness of these interventions in the Netherlands.

To allocate adolescents and their families to either one of the treatments, a well-known model, the Risk-NeedResponsivity (RNR) model, is often used. Following this model, the intensity of the treatment should be matched to risks and characteristics of the adolescent. The higher the risk of delinquent behavior, the more intensive treatment should be (Andrews and Bonta 2010; Andrews et al. 2006). The model implies that adolescents should be assigned to FFT unless there are indications that MST would be more suitable, such as serious delinquent behavior, a high risk that the family cannot provide a safe environment, and an increased risk of recidivism (Oudhof et al. 2009). In practice, this assignment procedure is followed by clinicians assigning youth to either FFT or MST. A previous Dutch study comparing both treatment populations found that more youth receiving MST had a court order than youth receiving FFT, and that youth receiving MST had more risk factors than those receiving FFT (Hendriks et al. 2014). This finding is in accordance with the results of a Swedish study which demonstrated that youth receiving MST had more behavioral problems than youth receiving FFT (Gustle et al. 2006). However, although both European studies showed that the most at risk youth received the most intensive treatment (i.e., MST), the model leaves room for interpretation and may be subject to chance. In fact, the target populations of MST and FFT show substantial overlap (Hendriks et al. 2014). Therefore, it appears that criteria used to allocate adolescents and their families to either one of the treatments are not fully mutually exclusive. Because these studies only looked into treatment populations and did not consider treatment effects, it remains unknown which intervention is the most effective for these overlapping target populations.

Therefore, the current study aimed to investigate the relative effectiveness of MST and FFT in the Netherlands. Because interventions are compared in their everyday practice settings, a quasi-experimental design was used, meaning that youth were not randomly allocated to one of the interventions. Without controlling for pre-treatment differences, a difference in outcomes may either be caused by the intervention itself, or by pre-treatment characteristics of adolescents and their families. Therefore, a propensity score (PS) was estimated and used to control for this 'allocation bias'.

The use of a PS in psychological research has increased in recent years (e.g., Austin 2011; Green and Stuart 2014; 
Thoemmes and Kim 2011; West et al. 2014). The current study used these tutorials and literature as a starting point in comparing MST and FFT. Because previous research has shown that youth receiving MST were more at risk than youth receiving FFT (Gustle et al. 2006; Hendriks et al. 2014), and because the only study to directly compare the effectiveness of FFT and MST thus far has taken risk level into account as well (Baglivio et al. 2014), the current study compared the treatment effects not only for the whole sample, but also in two subsamples of youth: with and without a court order. Having a court order can be interpreted as a risk factor and indicate the risk level of an adolescent before treatment. Based on the RNR model, more youth without a court order would be expected to be referred to FFT than to MST and more youth with a court order would be expected to receive MST.

With a growing body of research examining evidencebased treatment, and given today's stringent health care budgets, it seems only logical to allocate youth to a more intensive and likely more expensive treatment (i.e., MST) only when there is no effective alternative (i.e., FFT; Aos et al. 2004; Asscher et al. 2013; Vermeulen et al. 2017). By comparing evidence-based interventions, budget allocation and the assignment of youth to the right interventions can be optimized.

\section{Methods}

\section{Participants}

Because the assignment procedure following the RNR model implies that adolescents should be assigned to FFT unless there are indicators that MST would be more suitable (Oudhof et al. 2009), FFT was considered the reference treatment and MST the 'new' treatment. Between October, 2009 and June, 2014, 1714 adolescents and their families started either FFT $(N=640)$ or MST $(N=1074)$ at De Viersprong, institute for personality disorders and behavioral problems in the Netherlands. After finishing treatment, 697 (40.7\%) participants completed the primary outcome measure (i.e., the Child Behavior Checklist, CBCL). These were 275 (43\%) adolescents who had received FFT and 422 (39.3\%) adolescents who had received MST. Such a low percentage of completed questionnaires after treatment is not uncommon within Routine Outcome Monitoring (ROM) because data is not gathered for specific research purposes (Stichting Benchmark GGZ 2016). To reduce uncertainty in the statistical analyses and results, these 697 families formed the study sample for the statistical analyses. Adolescents who had received FFT and completed the primary outcome measure differed significantly from those who did not with regard to their country of birth, living situation, and whether or not they had a court order before treatment (see Table I in Online Supplemental Material). Adolescents who received MST and completed the assessment after finishing treatment differed from those who did not with regard to their country of birth, living situation, engagement in school or work, whether or not they had a court order before treatment, as well as the country of birth, level of education, and employment status of their primary caregiver, and whether or not this primary caregiver had a partner (see Table II in Online Supplemental Material).

In addition to the study sample of 697 adolescents, the effectiveness of the treatments was compared between the two subsamples of youth with and without a court order. Of the 422 adolescents who received MST, 246 had a court order and 168 had not (for 10 adolescents [2 FFT; 8 MST], the judicial status was unknown). For FFT, 71 adolescents had a court order, while 202 had not.

\section{Procedures}

As part of the treatment procedure, adolescents and their families filled in questionnaires for ROM at the beginning of and after completing treatment. Routine Outcome Monitoring is a measurementsystemtoroutinelycollectdataontheoutcomeof treatment, evaluateindividualtreatmentprogress, andprovide transparency regarding the effectiveness of treatment (Buwaldaetal.2011).WithinROM, adolescentsand theirfamilies provide consent concerning the collection of data and its use for quality control and research. The Medical Ethical Committee oftheErasmusMedicalCentreapproved thisstudy (METC-2015-124). The quality of treatment delivery of MST and FFT was monitored by the quality assurance systems of bothinterventions. These systems provide guidelines for therapist training and supervision, adherence to the treatment protocol, and treatmentduration. Inthecurrentstudy, alltherapists were trained and licensed to deliver the treatments. According to the treatmentmodel, they received weekly supervision from theirteamsupervisorand fromanindependentconsultant(i.e., working for the licensor of MSTor FFT instead of the provider organization itself). Data on treatment adherence and treatment duration were obtained from MST Institute and FFT LLC, who manage the quality assurance systems of MST and FFT, respectively. Withinthestudysample, themeantreatment duration of MST was 148.5 days, which was somewhat longer than the expected duration of 100 to 140 days according to the MST quality assurance system. For FFT, the mean treatment duration was 196.2 days, which was also above the expected duration (i.e., 90 to 150 days according to the FFT quality assurance system). Both MSTand FFT therapists were adherent to the treatment model, meaning they were consistently implementing themodel with theircases. Themean adherence score within MST was .53, which was in accordance with the norm of $\geq 0.50$ provided by MST Institute. Within FFT, the mean adherence score was 3.97, which was above the FFT LLC target of 3.0. 


\section{Measures}

\section{Baseline Measures}

Demographics To correct for initial differences between the treatment groups, an extensive set of questionnaires was completed at the beginning of the treatment. The therapist reported several demographics of the adolescents and their primary caregivers. Age, gender, country of birth, living situation, level of education, previous treatment, engagement in school or work, previous court orders, police contacts, and the relation with their father, mother, siblings, and peers were reported for each adolescent. Furthermore, the country of birth, level of education, employment status, and presence of a partner were reported for the primary caregivers (Praktikon/MST-NL, Sociaal Demografische Informatie. Ongepubliceerde vragenlijst [Demographic information], unpublished manuscript). Table 1 shows all demographic characteristics at baseline for both treatment groups.

Problem Behavior Furthermore, parents completed the CBCL (Achenbach and Rescorla 2001; Dutch version by Verhulst and van der Ende 2001a) and the youths themselves completed the Youth Self Report (YSR; Achenbach and Rescorla 2001; Dutch version by Verhulst and van der Ende 2001b). A youth's internalizing problem behavior, externalizing problem behavior, and the total score of the problem behavior were used for analyses. On both questionnaires, items were completed on a 3 -point scale (ranging from $0=$ never to $2=$ often). T-scores were computed and used for analyses. A higher Tscore indicates that an adolescent has more problems. Both CBCL and YSR scales were used to measure problem behavior from different perspectives. The Cronbach's alpha coefficients of the study sample for internalizing, externalizing, and total problem behavior measured with the CBCL were .88 , .93 , and .96 , respectively. For the YSR these coefficients were $.92, .90$, and .95 , respectively. The Cronbach's alpha coefficients found in the study sample were similar to those reported in the CBCL and YSR manual (i.e., CBCL: .90, .94, and .97, YSR: .90, .90, and .95 Achenbach and Rescorla 2001).

Parenting Stress Finally, until September, 2012, parenting stress was measured with the Nijmeegse Ouderlijke Stress Index (NOSI-R; De Brock et al. 2004) in which the primary caregiver completes 42 items on a 4-point scale (ranging from $1=$ fully disagree to $4=$ fully agree). These items are used to estimate a score for parenting stress wherein a higher score indicates more stress. The reliability coefficient was .95. From October, 2012 onwards, the Opvoedingsbelasting Vragenlijst (OBVL; Vermulst et al. 2012) was used to measure parenting stress. For this measure, the primary caregiver completes 34 items on a 4-point scale (ranging from $1=$ not true to 4 = very true). For an English version of the OBVL, see http:// www.praktikon.nl/wp-content/uploads/2016/03/obvl_en.pdf.
The scores of all items are summed for a total score regarding parenting stress. The alpha coefficient for this measure was .94 . Because parenting stress was measured with two different questionnaires, the deviance score of the scales was used to express the level of parenting stress for both questionnaires in one score concerning parenting stress. This was estimated by subtracting the normscore from the score of the adolescent and dividing this by the standard deviation of the norm group.

Treatment Variables Treatment variables, such as length of treatment and dosage of treatment, were not controlled for in the propensity score since these treatment characteristics are part of the treatment itself and the treatment is adapted to the specific situation of the adolescent and his or her family.

\section{Outcome Measures}

Primary Outcome Measure: Externalizing Problem Behavior Because both FFT and MST are primarily aimed at reducing externalizing problem behavior, this was defined as the primary outcome measure and was measured with the CBCL and YSR (Achenbach and Rescorla 2001). The primary caregiver reported the externalizing problems of the adolescent with the CBCL, while the youth himself reported this behavior with the YSR. Both measures were completed at the start and the end of treatment by completing 35 items on a 3 -point scale (ranging from $0=$ never to 2 =ften). T-scores were used for the analyses. A higher T-score indicates that an adolescent has more problems. The alpha reliability coefficient for the current sample at the end of the treatment using the CBCL and YSR is .94 and .88 respectively.

Secondary Outcome Measures Three secondary outcome measures were assessed at the end of the treatment: 1) whether or not the youth was living at home (i.e., the adolescent had not been placed out of home); 2) whether or not the adolescent was engaged in school or work for at least $20 \mathrm{~h}$ per week at the end of the treatment; and 3) whether or not the adolescent had new police contact due to inappropriate or illegal behavior during the treatment period. The therapist registered these treatment outcomes after treatment and in consultation with the primary caregiver. These three outcomes have been operationalized and standardized by MST Services to ensure that these outcomes are scored identically by all therapists (MST Institute 2016). This scoring procedure was also followed by FFT. The quality assurance systems of both treatments ensure that their ultimate outcomes are monitored by the therapist, the team supervisor, and the team consultant. 


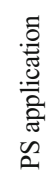

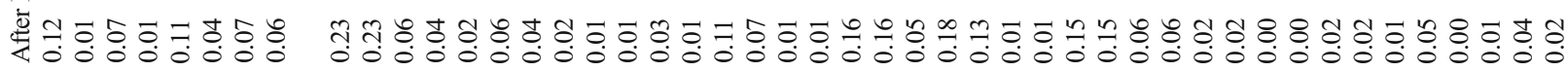

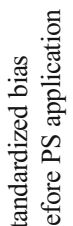

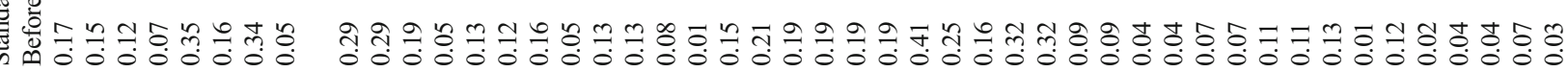

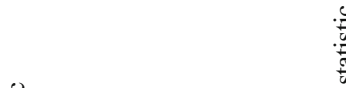

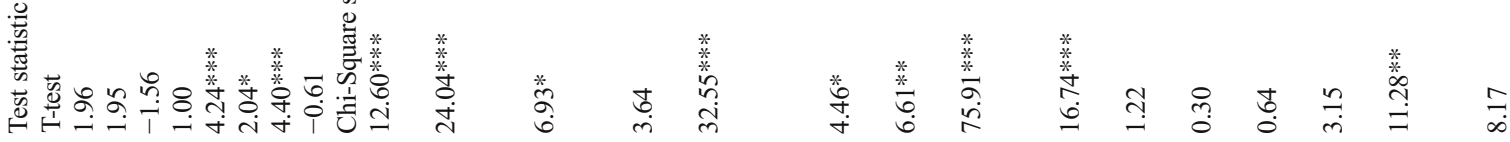

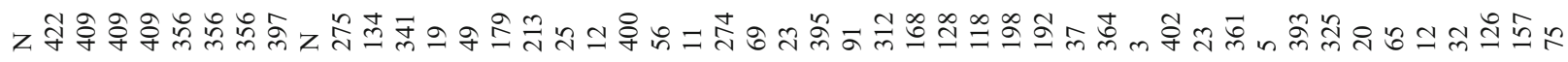
$\widetilde{\widetilde{\gamma}}$

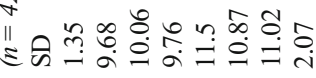

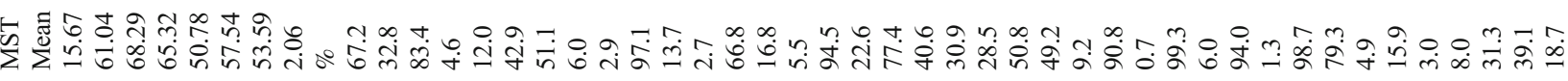

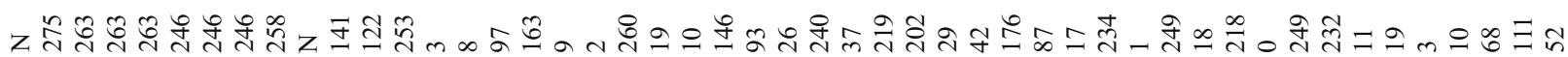

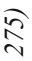

Е

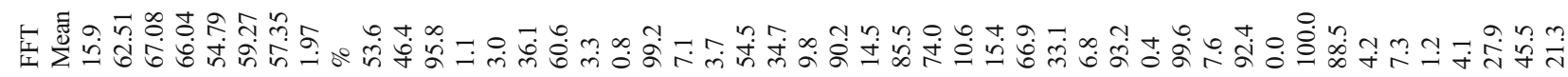
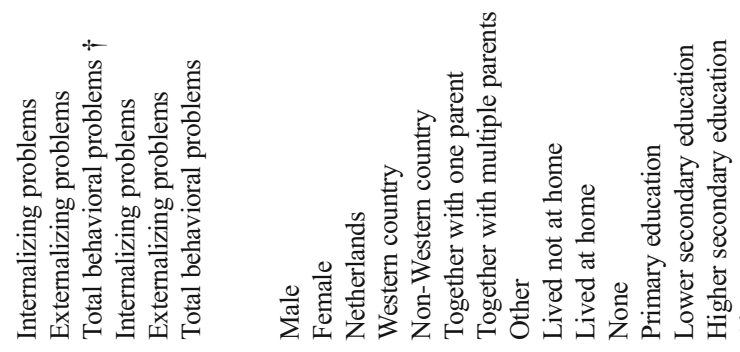

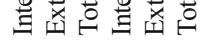

要部之

in

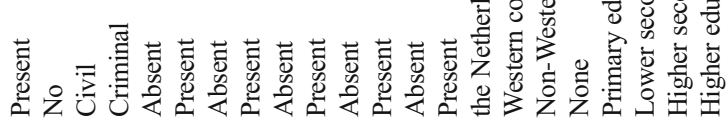

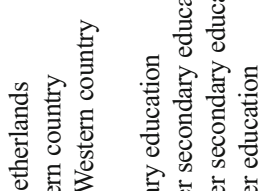

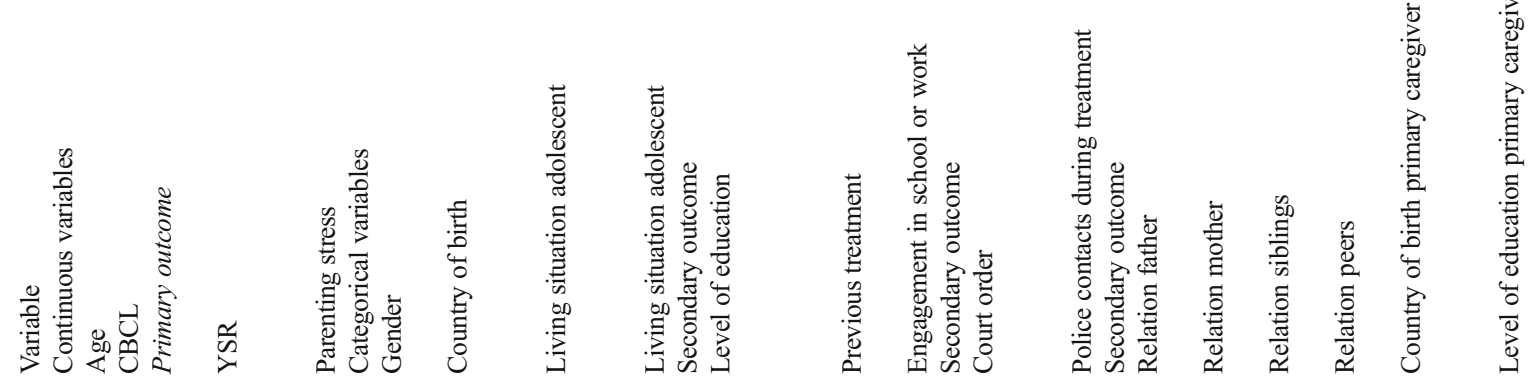




\section{Statistical Analysis}

Development of the Propensity Score The PS is defined as the conditional probability of assignment to an intervention given a set of observed, pre-treatment variables (Rosenbaum and Rubin 1983). Moreover, the PS is a balancing score which can be used to achieve a balanced distribution for the observed covariates of the treated and control group (Austin 2011). The PS was estimated in a univariate logistic regression function for the intervention groups. Here, MST is considered the treated group (coded as 1), and FFT the comparison group (coded as 0 ). This is because, according to the RNR model, adolescents should be assigned to FFT unless there are serious indications to assign an adolescent to MST (Oudhof et al. 2009). The observed pre-treatment variables of adolescents are the independent variables added to the model (Austin 2011; D'Agostino Jr 1998; Thoemmes and Kim 2011). These variables, the potential confounders, were selected for the PS model based on clinical knowledge and their expected relation to at least the outcome, and possibly to the treatment itself (Brookhart et al. 2006; Stuart 2010).

Weighting by the Propensity Score The PS was applied by weighting groups by the odds of their estimated PS score (Stuart 2010). Weighting by their odds was preferred because there were more treated MST cases than control FFT cases and the interest lies in the average treatment effect in the treated (ATT) rather than the average treatment effect (ATE; Stuart 2010). The ATT is the treatment effect in the adolescents who were actually treated with MST., iln other words, treatment outcomes for adolescents who received MST are compared with outcome s effects that would have been found if the same adolescents had received FFT (Harder et al. 2010; Stuart 2010). In contrast, the ATE is the difference between the outcomes if the entire patient group had been treated with MST and the outcome if all had been treated with FFT.

For the estimation of the ATT, the MST group wasweighted with 1 , while the FFT group was weighted with the PS score divided by one minus the PS score. The PS scores that showed no overlap in the treatment groups were removed. Though this restricts the generalizability of the results to cases for which overlap is present, removing cases without overlap allows for more precisely balancing the treatment arms (Harder et al. 2010).

Missing Indicator Approach The baseline covariates in the dataset of 697 adolescents who completed either FFT or MST had missing values. To manage these missing values, a missing indicator approach was used while estimating the PS (Cham and West 2016; D'Agostino Jr. et al. 2001; Harder et al. 2010; Rosenbaum and Rubin 1984; West et al. 2014). This method can be theoretically justified and works well to balance observed and missing value patterns across treatment 
groups without removing cases from the analysis (Cham and West 2016; Harder et al. 2010; Rosenbaum and Rubin 1984). In applying this method, the covariate and a missing indicator for this covariate were included in the PS estimation, coded 1 if there was a missing value for the covariate and 0 if not (D'Agostino Jr. et al. 2001; Haviland et al. 2007; Rosenbaum 2010). This method enables the use of all cases and balances observed values in the covariates, as well as the missing patterns of these covariates. After PS estimation, balance was assessed for the missing indicators and covariates without missing value substitution. In estimating treatment effects, the missing value substitution was also removed and missing indicators were not taken into account in estimating treatment effects (Haviland et al. 2007; Rosenbaum 2010).

Balance Assessment An important step in applying the PS is to assess the balance of the observed covariates between the two treatment arms (Stuart 2010). Balance was evaluated for the covariate without missing value substitution and for the missing indicators of the covariates (Harder et al. 2010; Haviland et al. 2007). Balance is achieved when the distribution of the baseline covariates is similar for the two interventions. Balance was assessed with the standardized bias which is independent of the sample size of the study. It was calculated by dividing the difference of the means of the covariates between the treated (MST) and comparison (FFT) group by the standard deviation of the treated group (i.e. MST; Austin 2009; Austin 2011; Harder et al. 2010; Stuart 2010; West et al. 2014). For the categorical covariates, the standardized bias was estimated per level (Harder et al. 2010).

The standardized bias was assessed before and after applying the PS to determine whether balance was achieved. The balance of the baseline covariates and missing indicators was assessed in the weighted sample. As a rule of thumb, it was assumed that balance was achieved when the standardized bias was less than .25 (Harder et al. 2010; Ho et al. 2007; West et al. 2014). The standardized bias of all covariates was carefully evaluated in addition to the balance of important, prognostic covariates (Ho et al. 2007).

In addition to the standardized bias, the variance ratio and the five-number-summary of the continuous covariates were assessed to determine whether these distributions were similar in higher order moments (Austin 2009). The distributions of the estimated variances are assumed to follow an Fdistribution (Austin 2009). The 2.5th and 97.5th percentiles can serve as a guide as to which variance ratios are tested to be equal between the treatment groups (Austin 2009). The fivenumber summaries should also be used as a qualitative assessment because there is no method to test the similarity of these summaries between treatment groups (Austin 2009).

Analysis of Treatment Effect Regression analysis was used to estimate treatment effect estimates in the weighted sample.
The treatment effect on the primary outcome measure was estimated with an OLS regression on the outcome and the treatment indicator as an independent variable. The effect of interventions on the secondary outcome measures was analyzed with logistic regression analyses. The results were used to calculate average risk differences and risk ratios, as these measures are collapsible among subgroups, in contrast to odds ratios (Goossens et al. 2015). These measures were estimated using ordinary cross tabs of the outcomes and treatment indicators in the weighted sample. For example, for the outcome 'living at home after treatment', the risk ratio was estimated as the probability of living at home after MST divided by the probability of living at home after FFT. The risk difference is the difference between these probabilities, estimated as the probability of living at home after MST minus the probability of living at home after FFT. For 'engaged in school or work' and 'new police contacts', the probability of being engaged in school or work and of having had police contact during treatment were looked at. The $95 \%$ confidence intervals of the final treatment effects were estimated using simple bootstrapping (Austin and Small 2014). In total, 5000 bootstrap samples were drawn from the weighted sample and in each bootstrapped sample, treatment effects were estimated. The 95\% interval was defined using a nonparametric percentile-based approach (Austin and Small 2014).

Subgroup Effects Finally, within the study sample, analyses were repeated for the subsamples of youth who had a court order (246 adolescents assigned to MST; 71 FFT) and youth who did not have a court order (168 MST; 202 FFT). Within each subsample, again the balance between the treatment arms was assessed and then the PS was applied by weighting groups by the odds of the estimated PS score (Green and Stuart 2014).

The analyses were performed with IBM SPSS for Windows, version 22 (IBM Corp 2013) and Microsoft Excel (2013). The $95 \%$ confidence intervals were bootstrapped in Stata 12 (StataCorp 2011).

\section{Results}

This section first describes the sample characteristics, then the balance in the covariates, and finally the treatment effect for respectively all adolescents in the study sample $(N=697)$, the subsample of adolescents without a court order $(n=370)$, and the subsample of adolescents with a court order $(n=317)$.

\section{Study Sample: All Adolescents}

Within the study sample of 697 adolescents, 422 completed MST and 275 completed FFT. Of the adolescents who completed MST, $67.2 \%$ were male and $83.4 \%$ were born in the 
Netherlands. For FFT, $53.6 \%$ of the adolescents were male and $95.8 \%$ were born in the Netherlands (see Table 1). Comparing the treatment groups on baseline characteristics showed substantial differences in internalizing, externalizing, and total behavioral problems reported by the adolescents. Furthermore, the treatment groups differed regarding gender, country of birth, the adolescent's living situation, level of education, previous treatment, engagement in school or work, previous court order, previous police contact, and country of birth and employment status of the primary caregiver (Table 1).

Balance Assessment Before the PS application, balance was assessed in all measured baseline characteristics (see Table 1). The largest imbalances were found for internalizing problems reported on the YSR, total behavioral problems measured with the YSR, gender, previous court order, and having had police contact before treatment,. The standardized bias of these baseline variables was higher than the accepted .25 (Table 1).

After weighting, balance for all of the covariates was found when the PS model contained all covariates except for the total score of behavioral problems measured by the CBCL (Table 1). Balance was inspected in the sample with overlapping PS scores. As a result, $8 \mathrm{MST}$ and 12 FFT cases were removed from the resulting sample. As Table 1 shows, values for the standardized bias after PS application are all lower than .25 . The values of the standardized bias for the missing indicator variables were also lower than .25 (Table III in Online Supplemental Material shows standardized bias for missing indicators before and after applying the PS).
Table 2 shows the variance ratio and five-number summaries of the continuous variables as additional measures for inspecting balance. In the weighted sample, the 2.5 th and 97.5th percentiles are .78 and 1.22. The estimated variance ratios are within these boundaries, and thus equality between treatment groups using this measure can be assumed. Moreover, the five-number summaries are also roughly equal in the PS weighted sample (Table 2).

Analysis of Treatment Effect After assessing the balance, the effectiveness of MST and FFT was compared in the outcome model. Table 3 shows no difference in externalizing problem behavior, with a small effect size of $d=0.01$ and $d=0.03$, on the CBCL and the YSR, respectively. The risk ratios (RR) and risk differences (RD) of the secondary outcomes showed no differences between MST and FFT for the proportion of youth living at home and having had police contact (Table 3). However, a significantly higher proportion of adolescents who had completed MST were engaged in school or work after treatment.

\section{Subsample: Youth without a Court Order}

Of the 697 adolescents in the study sample, 370 (168 MST; 202 FFT) had no court order before receiving the intervention. Of the adolescents who had completed MST, $61.5 \%$ were male and $90.3 \%$ were born in the Netherlands. For FFT, $52.3 \%$ of the adolescents were male and $97.4 \%$ were born in the Netherlands (for an extensive comparison of the treatment arms, see

Table 2 Variance ratio and 5-number summary of continuous covariates after PS application in full sample $(N=697)$

\begin{tabular}{|c|c|c|c|c|c|c|c|c|}
\hline & & & Variance ratio & Minimum & 25 th percentile & Median & 75th percentile & Maximum \\
\hline \multirow[t]{2}{*}{ Age } & & FFT & 0.79 & 12.10 & 14.76 & 15.95 & 16.79 & 20.39 \\
\hline & & MST & & 11.07 & 14.80 & 15.83 & 16.72 & 18.34 \\
\hline \multirow[t]{6}{*}{ CBCL } & Internalizing problems & FFT & 0.96 & 33.00 & 55.00 & 61.00 & 68.00 & 88.00 \\
\hline & & MST & & 33.00 & 55.00 & 62.00 & 69.00 & 82.00 \\
\hline & Externalizing problems & FFT & 0.92 & 34.00 & 61.00 & 70.00 & 74.00 & 92.00 \\
\hline & & MST & & 34.00 & 63.00 & 69.00 & 75.00 & 88.00 \\
\hline & Total behavioral problems & FFT & 0.87 & 24.00 & 60.00 & 68.28 & 71.00 & 85.00 \\
\hline & & MST & & 27.00 & 60.00 & 67.00 & 72.00 & 83.00 \\
\hline \multirow[t]{6}{*}{ YSR } & Internalizing problems & FFT & 0.97 & 30.00 & 44.00 & 54.00 & 61.00 & 83.00 \\
\hline & & MST & & 27.00 & 44.00 & 50.00 & 58.00 & 85.00 \\
\hline & Externalizing problems & FFT & 1.02 & 29.00 & 52.00 & 59.00 & 66.00 & 80.00 \\
\hline & & MST & & 29.00 & 51.00 & 58.00 & 66.00 & 93.00 \\
\hline & Total behavioral problems & FFT & 1.06 & 28.00 & 47.00 & 56.00 & 62.00 & 77.00 \\
\hline & & MST & & 26.00 & 46.00 & 54.00 & 62.00 & 82.00 \\
\hline \multirow[t]{2}{*}{ Parenting stress } & & FFT & 1.21 & -1.40 & 0.61 & 1.98 & 3.34 & 7.78 \\
\hline & & MST & & -1.52 & 0.45 & 1.92 & 3.42 & 8.95 \\
\hline
\end{tabular}

$\$$ In the weighted sample the 2.5 th and 97.5 th percentiles of the F-distribution are 0.78 and 1.22 respectively

CBCL, Child Behavior Checklist, YSR, Youth Self Report, PS, propensity score 
Table 3 Comparing MST with FFT average treatment effects of the treated

\begin{tabular}{|c|c|c|c|c|}
\hline \multirow[t]{2}{*}{ All adolescents: } & \multicolumn{4}{|c|}{ Study sample $(N=697)$} \\
\hline & $\mathrm{B} \dagger$ & $95 \% \mathrm{CI}$ & & \\
\hline Externalizing problem behavior CBCL & 0.14 & $-3.23,3.49$ & & \\
\hline \multirow[t]{2}{*}{ Externalizing problem behavior YSR } & -0.29 & $-2.45,1.90$ & & \\
\hline & $\mathrm{RR}$ & $95 \% \mathrm{CI}$ & $\mathrm{RD}$ & $95 \% \mathrm{CI}$ \\
\hline Police contact during treatment & 1.61 & $0.98,3.08$ & 0.10 & $-0.01,0.19$ \\
\hline Living at home after treatment & 0.98 & $0.96,1.01$ & -0.02 & $-0.04,0.01$ \\
\hline Engaged in school or work after treatment & $1.27 * *$ & $1.06,1.57$ & $0.19 *$ & $0.05,0.33$ \\
\hline \multirow[t]{2}{*}{ Youth without a court order: } & \multicolumn{4}{|c|}{ Study sample $(n=370)$} \\
\hline & $\mathrm{B}+$ & $95 \% \mathrm{CI}$ & & \\
\hline Externalizing problem behavior CBCL & $-3.24 *$ & $-5.97,-0.39$ & & \\
\hline \multirow[t]{2}{*}{ Externalizing problem behavior YSR } & $-3.33^{*}$ & $-5.81,-0.86$ & & \\
\hline & $\mathrm{RR}$ & $95 \% \mathrm{CI}$ & $\mathrm{RD}$ & $95 \% \mathrm{CI}$ \\
\hline Police contact during treatment & 1.20 & $0.72,2.77$ & 0.05 & $-0.10,0.20$ \\
\hline Living at home after treatment & 0.97 & $0.94,1.01$ & -0.03 & $-0.06,0.01$ \\
\hline Engaged in school or work after treatment & 1.09 & $0.94,1.31$ & 0.07 & $-0.05,0.21$ \\
\hline \multirow[t]{2}{*}{ Youth with a court order: } & \multicolumn{4}{|c|}{ Study sample $(n=317)$} \\
\hline & $\mathrm{B}$ & $95 \% \mathrm{CI}$ & & \\
\hline \multirow{2}{*}{$\begin{array}{l}\text { Externalizing problem behavior CBCL } \\
\text { Externalizing problem behavior YSR }\end{array}$} & \multicolumn{4}{|c|}{ Balance not achieved II } \\
\hline & $\mathrm{RR}$ & $95 \% \mathrm{CI}$ & $\mathrm{RD}$ & $95 \% \mathrm{CI}$ \\
\hline $\begin{array}{l}\text { Police contact during treatment } \\
\text { Living at home after treatment }\end{array}$ & \multicolumn{4}{|c|}{ Balance not achieved /I } \\
\hline Engaged in school or work after treatment & & & & \\
\hline
\end{tabular}

* Confidence interval does not contain $0, * *$ Confidence interval does not contain $1, \uparrow$ Model constant in weighted sample after applying the PS, CBCL, 61.62, YSR, 54.42, $\$$ Model constant in weighted sample after applying the PS, CBCL, 66.98, YSR, 58.47, \| Balance was not achieved, therefore the differential effectiveness of FFT and MST could not be estimated

MST, Multisystemic Therapy, FFT, Functional Family Therapy, CI, confidence interval, RD, relative difference, $\mathrm{RR}$, relative risk
Table IV in Online Supplemental Material). Comparing the treatment groups within this subsample on baseline characteristics showed significant differences in age, externalizing and total behavioral problems measured with the CBCL, parenting stress, country of birth, level of education, previous treatment, engagement in school or work, and previous police contact (Table IV in Online Supplemental Material).

Balance Assessment Before the PS application, the largest imbalances (i.e., standardized bias higher than the accepted .25) were found for age, externalizing problems on the CBCL, level of education, previous treatment, and having had police contact before treatment (Table IV in Online Supplemental Material). After PS application, balance was found when all covariates except for the total score of behavioral problems measured by the CBCL were selected for the PS estimation. Before inspecting balance, $11 \mathrm{MST}$ and $29 \mathrm{FFT}$ cases were removed for which there was no overlap on the PS scores. Except for the standardized bias of the level of education of the adolescent, values of the standardized bias after PS application were lower than .25 (Table IV in Online Supplemental Material). Values for the standardized bias for the missing indicator variables were also lower than .25 (Table V in Online Supplemental Material). The variance ratios of the continuous variables, except for parenting stress, were within the boundaries defined by the 2.5 th and 97.5 th percentiles of the F-distribution in the weighted sample. Thus, except for parenting stress, balance can be assumed given these values (Table VI in Online Supplemental Material). The five-number summaries show roughly equally distributed continuous variables between the treatment groups (Table VI in Online Supplemental Material).

Analysis of Treatment Effect In the subsample of adolescents without a court order, MST and FFT differed significantly in terms of externalizing problem behavior. Multisystemic Therapy resulted in lower scores on externalizing problem behavior than FFT, with a medium effect size of $d=0.32$ and $d=0.34$, respectively. The differences (RR and RD) between MST and FFT on the three secondary outcomes were insignificant (Table 3). 


\section{Subsample: Youth with a Court Order}

In total, 317 (246 MST; 71 FFT) of the 697 adolescents in the study sample had a court order before starting treatment. Of the adolescents who had completed MST, $70.4 \%$ were male and $78.2 \%$ were born in the Netherlands, while for FFT, $56.1 \%$ of the adolescents were male and $91 \%$ were born in the Netherlands (for an extensive comparison of the treatment arms, see Table VII in Online Supplemental Material). Multisystemic Therapy and FFT showed significant differences in terms of age, externalizing behavioral problems measured with the CBCL, internalizing problems measured with the YSR, gender, relation with father, and employment status of the primary caregiver at the baseline (Table VII in Online Supplemental Material).

Balance Assessment Before the PS application, the standardized bias was higher than the accepted .25 for age, externalizing problem behavior on the CBCL, internalizing problems on the YSR, gender, relation with father, and employment status of the primary caregiver (Table VII in Online Supplemental Material). After PS application, balance was not achieved using different PS estimations. Either there were some variables with a standardized bias higher than .25 , or there were numerous variables with a standardized bias just below.25. Furthermore, if balance was assessed in the sample with overlapping scores on the PS, roughly 60-80 MST cases had to be removed each time when testing various PS estimations. This indicates that the sample of adolescents assigned to MST could not be balanced to the sample of adolescents assigned to FFT (West et al. 2014).

Analysis of Treatment Effect Because there was not confidence in assuming balance was achieved in this subsample of youth with a court order, the effectiveness could not be estimated without ensuring the control of allocation bias.

\section{Discussion}

Using the PS method to control for the non-random assignment of adolescents to either MST or FFT, this study compared these two interventions on their effectiveness in the Netherlands. In the study sample, target populations were balanced and no differences between the interventions were found regarding externalizing problem behavior. Some additional results were found: adolescents assigned to MST were more often engaged in school or work after treatment. This treatment objective likely receives greater emphasis during MST than during FFT.

In the present study, the average treatment effect of the treated was estimated and the finding suggests that adolescents who receive MST may display the same treatment effects if they would have received FFT. This treatment effect, however, is only applicable for adolescents and their sample characteristics for whom there were outcome measurements after treatment. Finding only a few differences when comparing the effectiveness of MST and FFT in the overall study sample is in accordance with previous findings by Baglivio et al. (2014).

As the present study demonstrates that adolescents with a court order - interpreted as a possible risk factor following the RNR-model (Andrews et al. 2006; van der Laan et al. 2010) - were more often assigned to MST (246 MST; 71 FFT), MST could also be expected to be more effective in this subsample. However, due to the incomparability of the FFT and MST subsamples of youth with a court order, the present study cannot confirm this. Furthermore, following the RNR model, FFT could at least be expected to be effective in the subsample of adolescents without a court order, as these adolescents would be expected to have lower risks, and, therefore, less intensive treatment would be adequate (Andrews et al. 2006; van der Laan et al. 2010). It was shown that FFT was effective, as it reduced externalizing problems from 67.08 on average (Table 1) to 61.62 on average (model constant in the weighted sample after applying the PS). However, MST was more effective in reducing externalizing problems in the subsample of youth without a court order. This may be explained by the fact that a more intensive treatment in a less severe target population is always likely to be more effective, but the question remains as to whether it is appropriate and proportional treatment. Furthermore, it could be explained by the fact that, although some risk factors were less present in the group without a court order, such as engagement in school or police contact (Table I and IV in Online Supplemental Material), this group nevertheless reported more problem behavior measured with the CBCL and the YSR (Tables I and IV in Online Supplemental Material). Another explanation may be that having or not having a court order only provides a rough indication of the risk level of an adolescent, while clinicians assign adolescents to either MST or FFT based on other risk factors as well. The RNR model thus leaves room for interpretation, or a single characteristic cannot fully represent the risk level of an adolescent. For the secondary outcomes, however, no differences were found between the interventions, though these outcomes may be highly relevant to society. This should be taken into account when interpreting the overall effectiveness of the interventions in this subgroup. Furthermore, future research could focus on the applicability and validity of a checklist based on the RNR model, for example, to support stepped care when applicable, and assign adolescents directly to more intensive interventions when needed (Krugten et al. 2016).

In addition to the effectiveness and assignment procedures of the interventions, and with stringent health care budgets, the costs of an intervention should be taken into account. If costs of 
a more effective intervention are higher than the costs of its alternative, it can be worthwhile to compare the interventions and their cost-effectiveness. Previous studies in the US and UK have shown MST to be cost-effective compared with alternatives like individual therapy (Cary et al. 2013; Klietz et al. 2010). The cost-benefit ratio of FFT compared to MST in the US has been shown to be in favor of FFT (Lee et al. 2012). In the Netherlands, Vermeulen et al. (2017) compared MST to treatment as usual, including FFT, and found MST to be more cost-effective. Thus, cost-effectiveness depends on the context of the study (e.g., sample or country). With regard to the current study, it would for example be beneficial to implement a costeffectiveness analysis in the subsample of adolescents without a court order. In this subsample, MST was more effective at reducing externalizing problems than FFT. Although it is unknown what the precise costs of MST and FFT are in the Netherlands, it is expected that MST is more expensive due to the intensity of the intervention. Cost-effectiveness analysis could reveal whether additional costs for MST are worth the higher effects. Future research should focus on estimating the exact costs of MST and FFT in the Netherlands and on estimating health services use of this population to indeed estimate the cost-effectiveness. Moreover, it is of interest to determine the cost-effectiveness of intervention options when following a stepped care procedure (i.e., should youth with a lower risk be assigned to MST directly, or should a less intensive option be the first choice).

Comparing evidence-based interventions within overlapping target populations could eventually result in greater knowledge about which interventions work best for whom (Yirmiya 2010). Therefore, it is important to examine treatment through client interactions and understand and study the assignment procedure based on the RNR model in greater detail. However, given the broad range of interventions currently available, it seems even more necessary to study practice elements or program elements of interventions to determine overlapping, effective elements (Chorpita and Daleiden 2009; Evenboer et al. 2012; Lee et al. 2014). Furthermore, it would be of interest to compare the long-term effects of MST and FFT to find out whether their comparative effectiveness changes over time.

This effectiveness study also shows that using clinical practice data, like ROM data, is worthwhile for evaluating treatments. It increases both the external validity of the study and the clinical utility, because data was gathered in regular clinical practice and sample selection bias is less present (Hodgson et al. 2007). The current study shows that the PS method is a useful and important method for using these data (West et al. 2014). It is, however, relevant to evaluate the chosen treatment outcomes in light of the selected dataset. The current study selected data from the Viersprong and not from other youth care institutions. Moreover, of the data available, a sample was selected for which there was an outcome measure after treatment. The study sample within which the comparative effectiveness was studied consisted of adolescents with overall less risk factors (i.e., less reported court orders, see Table I and II in Online Supplemental Material) compared to the group for which no data was available after treatment, which could in turn result in less differences between interventions because this group might have shown better results overall. Thus, although clinical practice data were used, the findings can only be generalized to the selected group of adolescents and the findings should be interpreted in light of this sample selection. On the one hand, this study sample is likely larger and has less sample selection bias compared to data from randomized clinical trials (RCTs). On the other hand, using observational data still merits reflection on the generalizability of the findings and evaluation given the selections, regardless of the study design (Stuart et al. 2011). Furthermore, partial replication of a previous study (Baglivio et al. 2014) supports prior evidence and shows that the results are robust across different clinical settings and study designs (Duncan et al. 2014).

Because our study is an effectiveness study and not an efficacy study, the interventions were studied as delivered in daily clinical practice as opposed to under highly controlled circumstances. In an efficacy study, interventions are more standardized and studied in rather homogeneous populations (Glasgow et al. 2003; Nordon et al. 2016; Singal et al. 2014). Though MST and FFT are both monitored by a quality system, follow detailed protocols, and require therapists to have completed specific training, the population treated, the duration and intensity of the treatment, and adherence of therapists to the treatment protocol may vary as a result of adapting the treatment to ever-changing circumstances in daily clinical practice. We chose not to control for such variations within and differences between the interventions, because then our study would no longer fully represent the effectiveness of the services as provided. Future research could be of interest to define treatment variables that should be reckoned with in clinical practice, such as specific or common program or practice elements that are important to obtain favorable treatment outcomes.

Despite the clinical relevance and use of this study, some limitations merit reflection. First, although a wide range of initial differences between adolescents in the treatment arms were controlled for, there could still be differences that were unmeasured and thus not controlled for. For example, the quality of life of the adolescent was not measured. This could have led to hidden biases in the presented results (Rosenbaum 1991; Shadish 2013). Second, though a response rate of about $40 \%$ is common when using clinical practice data from ROM in the Netherlands that are not gathered for specific research purposes, there were a number of families who did not complete the CBCL at the end of the treatment. When comparing adolescents who did and did not complete this primary outcome measure, there were differences within the MST and 
FFT group. As a result, the external validity of this study is not optimal because the effect of the treatments in the group with missing data could not be established. Third, we did not use a control group of adolescents without any treatment. It would, however, be helpful to include a reference treatment when policy makers have to decide on the use of these two evidence-based interventions. Fourth, although the chosen method was thoroughly considered, and all assumptions were checked, the choice of methods could influence the outcomes. There could, for example, be other estimation methods (e.g., matching with the PS or stratification using the PS), which arrive even closer to the true effect (Cham and West 2016; Harder et al. 2010). Even more, using different approaches can help reducing uncertainty surrounding outcomes. Finally, the subgroup that was chosen to indicate risk level according to the RNR model was based on having a court order or not, but other demographic characteristics (in combination) could have been used to study subgroups as well, such as living situation or education level.

In conclusion, the current study found few differences in the relative effectiveness of MST and FFT. This paper also stresses the necessity of investigating effects within subgroups of adolescents, as conclusions can change when looking at specific subgroups. Though RCTs are considered to be most effective for evaluating treatment options, using clinical practice data is certainly a viable alternative when carefully applied. By thoroughly controlling for treatment selection, the approach even enhances external validity because sample selection is less present than in RCTs (Stuart et al. 2011).

Acknowledgements We would like to thank Iris Yocarini and Jermain Rambhadjan for helping in constructing the dataset, searching literature, and starting preliminary analyses.

\section{Compliance with Ethical Standards}

Conflict of Interest The authors declare that they have no conflict of interest.

Ethical Approval All procedures performed in studies involving human participants were in accordance with the ethical standards of the institutional and/or national research committee and with the 1964 Helsinki declaration and its later amendments or comparable ethical standards.

Informed Consent Informed consent was obtained from all individual participants included in the study; The adolescents and their families gave their consent to collect data and to use these data for quality control and research.

Open Access This article is distributed under the terms of the Creative Commons Attribution 4.0 International License (http:// creativecommons.org/licenses/by/4.0/), which permits unrestricted use, distribution, and reproduction in any medium, provided you give appropriate credit to the original author(s) and the source, provide a link to the Creative Commons license, and indicate if changes were made.

\section{References}

Achenbach, T. M., \& Rescorla, L. A. (2001). Manual for the ASEBA school-age forms and profiles. Burlington: University of Vermont, Research Center for Children, Youth \& Families.

Alexander, J. F., \& Sexton, T. L. (2002). Functional family therapy: A model for treating high-risk, acting-out youth. In: F. W. Kaslow \& J. Lebow (Eds.), Comprehensive handbook of psychotherapy: Integrativeleclectic (pp. 111-132). New York: John Wiley.

Andrews, D. A., \& Bonta, J. (2010). Rehabilitating criminal justice policy and practice. Psychology, Public Policy and Law, 16, 39-55. https:// doi.org/10.1037/a0018362.

Andrews, D. A., Bonta, J., \& Wormith, J. S. (2006). The recent past and near future of risk and/or need assessment. Crime \& Delinquency, 52, 7-27. https://doi.org/10.1177/0011128705281756.

Aos, S., Lieb, R., Mayfield, J., Miller, M., \& Pennucci, A. (2004). Benefits and costs of prevention and early intervention programs for youth. Olympia: Washington State Institute for Public Policy.

Asscher, J. J., Dekovic, M., Manders, W. A., van der Laan, P. H., \& Prins, P. J. M. (2013). A randomized controlled trial of the effectiveness of multisystemic therapy in the Netherlands: Post-treatment changes and moderator effects. Journal of Experimental Criminology, 9, 169-187. https://doi.org/10.1007/s11292-012-9165-9.

Austin, P. C. (2009). Balance diagnostics for comparing the distribution of baseline covariates between treatment groups in propensity score matched samples. Statistics in Medicine, 28, 3083-3107. https://doi. org/10.1002/sim.3697.

Austin, P. C. (2011). An introduction to propensity score methods for reducing the effects of confounding in observational studies. Multivariate Behavioral Research, 46, 399-424. https://doi.org/10. 1080/00273171.2011.568786.

Austin, P. C., \& Small, D. S. (2014). The use of bootstrapping when using propensity score matching without replacement: A simulation study. Statistics in Medicine, 33, 4306-4319. https://doi.org/10.1002/sim. 6276.

Baglivio, M. T., Jackowski, K., Greenwald, M. A., \& Wolff, K. T. (2014). Comparison of multisystemic therapy and functional family therapy effectiveness: A multiyear statewide propensity score matching analysis of juvenile offenders. Criminal Justice and Behavior, 41, 1033-1056. https://doi.org/10.1177/0093854814543272.

Blueprints for healthy youth development. (2015). Factsheet Functional Family Therapy (FFT). Retrieved from http://www.blueprintsprograms.com/ factSheet.php?pid=0a57cb53ba59c46fc4b692527a38a87c78d84028

Breuk, R. E., Sexton, T. L., van Dam, A., Disse, C., Doreleijers, T. A. H., Slot, W. N., \& Rowland, M. K. (2006). The implementation and the cultural adjustment of functional family therapy in a Dutch psychiatric day-treatment center. Journal of Marital and Family Therapy, 32, 515-529. https://doi.org/10.1111/j.1752-0606.2006.tb01625.x.

Bronfenbrenner, U. (1979). The ecology of human development. Cambridge: Harvard University Press.

Brookhart, M. A., Schneeweiss, S., Rothman, K. J., Glynn, R. J., Avorn, J., \& Stürmer, T. (2006). Variable selection for propensity score models. American Journal of Epidemiology, 163, 1149-1156. https://doi.org/10.1093/aje/kwj149.

Buwalda, V. J. A., Nugter, M. A., Swinkels, J. A., \& Mulder, C. L. (2011). Praktijkboek ROM in de ggz: Een leidraad voor gebruik en implementatie van meetinstrumenten [Manual ROM in mental health care: Guidance for use and implementation of measurement instruments]. Utrecht: De Tijdstroom uitgeverij B.V.

Cary, M., Butler, S., Baruch, G., Hickey, N., \& Byford, S. (2013). Economic evaluation of multisystemic therapy for young people at risk for continuing criminal activity in the UK. PLOS ONE, 8, e61070. https://doi.org/10.1371/journal.pone.0061070.

Cham, H., \& West, S. G. (2016). Propensity score analysis with missing data. Psychological Methods. https://doi.org/10.1037/met0000076. 
Chorpita, B. F., \& Daleiden, E. L. (2009). Mapping evidence-based treatments for children and adolescents: Application of the distillation and matching model to 615 treatments from 322 randomized trials. Journal of Consulting and Clinical Psychology, 77, 566-579. https://doi.org/10.1037/a0014565.

Chorpita, B. F., Daleiden, E. L., Ebesutani, C., Young, J., Becker, K. D., Nakamura, B. J., . . . Starace, N. (2011). Evidence-based treatments for children and adolescents: An updated review of indicators of efficacy and effectiveness. Clinical Psychology: Science and Practice, 18, 154 172. https://doi.org/10.1111/j.1468-2850.2011.01247.x.

D’Agostino Jr., R. B., Lang, W., Walkup, M., Morgan, T., \& Karter, A. (2001). Examining the impact of missing data on propensity score estimation in determining the effectiveness of self-monitoring of blood blucose (SMBG). Health Services and Outcomes Research Methodology, 2, 291-315. https://doi.org/10.1023/A:1020375413191.

D'Agostino Jr., R. B. (1998). Propensity score methods for bias reduction in the comparison of a treatment to a non-randomized control group. Statistics in Medicine, 17, 2265-2281. https://doi.org/10.1002/(SICI) 1097-0258(19981015)17:19<2265::AID-SIM918>3.0.CO;2-B.

De Brock, A., Vermulst, A., Gerris, J., Veerman, J. W., \& Abidin, R. (2004). Nijmeegse Ouderlijke Stress Index-R. Voorlopige handleiding [Nijmegen Parenting Stress Index Revised]. Nijmegen: Behavioural Science Institute.

Duncan, G. J., Engel, M., Claessens, A., \& Dowsett, C. J. (2014). Replication and robustness in developmental research. Developmental Psychology, 50, 2417-2425. https://doi.org/10. 1037/a0037996.

Evenboer, K. E., Huyghen, A. N., Tuinstra, J., Knorth, E. J., \& Reijneveld, S. A. (2012). A taxonomy of care for youth: Results of an empirical development procedure. Research on Social Work Practice, 22, 637-646. https://doi.org/10.1177/1049731512448546.

Glasgow, R. E., Lichtenstein, E., \& Marcus, A. C. (2003). Why don't we see more translation of health promotion research to practice? Rethinking the efficacy-to-effectiveness transition. American Journal of Public Health, 93, 1261-1267. https://doi.org/10.2105/ AJPH.93.8.1261.

Goossens, L., Redekop, K., \& van Gils, C. (2015). Noncollapsibility and censoring: What's the bias in estimating effects on survival? Epidemiology, 26, e1. https://doi.org/10.1097/EDE.0000000000000197.

Green, K. M., \& Stuart, E. A. (2014). Examining moderation analyses in propensity score methods: Application to depression and substance use. Journal of Consulting and Clinical Psychology, 82, 773-783. https://doi.org/10.1037/a0036515.

Gustle, L.-H., Hansson, K., Sundell, K., Lundh, L.-G., \& Lofhölm, C. A. (2006). Blueprints in Sweden. Symptom load in Swedish adolescents in studies of functional family therapy (FFT), multisystemic therapy (MST) and multidimensional treatment Foster Care (MTFC). Nordic Journal of Psychiatry, 61, 443-451. https://doi. org/10.1080/08039480701773196.

Harder, V. S., Stuart, E. A., \& Anthony, J. C. (2010). Propensity score techniques and the assessment of measured covariate balance to test causal associations in psychological research. Psychological Methods, 15, 234-249. https://doi.org/10.1037/a0019623.

Haviland, A., Nagin, D. S., \& Rosenbaum, P. R. (2007). Combining propensity score matching and group-based trajectory analysis in an observational study. Psychological Methods, 12, 247-267. https://doi.org/10.1037/1082-989X.12.3.247.

Hendriks, M. E. D., Lange, A. M. C., Boonstoppel-Boender, M., \& van der Rijken, R. E. A. (2014). Functional family therapy en multi Systeem Therapie: Een vergelijking van doelgroepen [functional family therapy and multisystemic therapy: A comparison of target populations]. Orthopedagogiek: Onderzoek en Praktijk, 53, 355-366.

Henggeler, S. W. (2011). Efficacy studies to large-scale transport: The development and validation of multisystemic therapy programs. Annual Review of Clinical Psychology, 7, 351-381. https://doi.org/ 10.1146/annurev-clinpsy-032210-104615.
Henggeler, S. W., Schoenwald, S. K., Borduin, C. M., Rowland, M. D., \& Cunningham, P. B. (2009). Multisystemic therapy for antisocial behavior in children and adolescents (2nd ed.). New York: The Guilford Press.

Ho, D. E., Imai, K., King, G., \& Stuart, E. A. (2007). Matching as nonparametric preprocessing for reducing model dependence in parametric causal inference. Political Analysis, 15, 199-236. https://doi. org $/ 10.1093 / \mathrm{pan} / \mathrm{mpl013.}$

Hodgson, R., Bushe, C., \& Hunter, R. (2007). Measurement of long-term outcomes in observational and randomised controlled trials. British Journal of Psychiatry, 191, 78-84. https://doi.org/10.1192/bjp.191. 50.s78.

IBM Corp. (Released 2013). IBM SPSS statistics for windows, version 22.0. Armonk: IBM Corp.

Klietz, S. J., Borduin, C. M., \& Schaeffer, C. M. (2010). Cost-benefit analysis of multisystemic therapy with serious and violent juvenile offenders. Journal of Family Psychology, 24, 657-666.

Krugten, F. C., Kaddouri, M., Goorden, M., van Balkom, A. J., Ruhé, H. G., van Schaik, D. J., et al. (2016). Feasibility, reliability and validity of the decision too unipolar depression (DTUD) in identifying patients with major depressive disorder in need of highly specialized care. Value in Health, 19, A529. https://doi.org/10.1016/j.jval.2016. 09.1063 .

Lee, S., Aos, S., Drake, E., Pennucci, A., Miller, M., \& Anderson, L. (2012). Return on investment: Evidence-based options to improve statewide outcomes. Olympia: Washington State Institute for Public Policy.

Lee, B. R., Ebesutani, C., Kolivoski, K. M., Becker, K. D., Lindsey, M. A., Brandt, N. E., et al. (2014). Program and practice elements for placement prevention. A review of interventions and their effectiveness in promoting home-based care. American Journal of Orthopsychiatry, 84, 244-256. https://doi.org/10.1037/h0099811.

Microsoft Excel (2013). Microsoft Office, Excel, version 2013. Washington: Microsoft.

MST Institute. (2016). Frequently asked questions. MST Institute enhanced website. Retrieved from https://www.msti.org/documents/ EW FAQs.pdf.

Nordon, C., Karcher, H., Groenwold, R. H. H., Zöllner Ankarfeldt, M., Pichler, F., Chevrou-Severac, H., Rossignol, M., Abbe, A., Abenhaim, L., \& (on behalf of the GetReal consortium). (2016). The "Efficacy-Effectiveness Gap": Historical background and current conceptualization. Value in Health, 19, 75-81. https://doi.org/ 10.1016/j.jval.2015.09.2938.

Oudhof, M., Ten Berge, I., \& Berger, M. (2009). Checklist MST/FFT. De ontwikkeling van een indicatie-instrument voor MST en FFT in de vorm van een checklist [Checklist MST/FFT. The development of a checklist-instrument to indicate assignment to MST and FFT]. Utrecht: Nederlands Jeugdinstituut.

Rosenbaum, P. R. (1991). Discussing hidden bias in observational studies. Annals of Internal Medicine, 115, 901-905. https://doi.org/10. 7326/0003-4819-115-11-901.

Rosenbaum, P. R. (2010). Design of observational studies. New York: Springer-Verlag. https://doi.org/10.1007/978-1-4419-1213-8.

Rosenbaum, P. R., \& Rubin, D. B. (1983). The central role of the propensity score in observational studies for causal effects. Biometrika, 70, 41-55. https://doi.org/10.1017/cbo9780511810725.016.

Rosenbaum, P. R., \& Rubin, D. B. (1984). Reducing bias in observational studies using subclassification on the propensity score. Journal of the American Statistical Association, 79, 516-524. https://doi.org/ 10.1080/01621459.1984.10478078.

Sexton, T. L., \& Alexander, J. F. (2000). Functional family therapy. Office of Juvenile Justice and Delinquency Prevention. Juvenile Justice Bulletin, 1, 1-7.

Sexton, T. L., \& Alexander, J. F. (2003). Functional family therapy for atrisk adolescent and their families (chapter 6). In F. W. Kaslow \& T. Patterson (Eds.), Comprehensive handbook of psychotherapy: 
Cognitive-behavioral approaches (volume 2). New York: John Wiley \& Sons, Inc..

Sexton, T., \& Turner, C. W. (2010). The effectiveness of functional family therapy for youth with behavioral problems in a community practice setting. Journal of Family Psychology, 24, 339-348. https://doi.org/ 10.1037/a0019406.

Shadish, W. R. (2013). Propensity score analysis: Promise, reality and irrational exuberance. Journal of Experimental Criminology, 25, 129-144. https://doi.org/10.1007/s11292-012-9166-8.

Singal, A. G., Higgins, P. D. R., \& Waljee, A. K. (2014). A primer on effectiveness and efficacy trials. Clinical and Translational Gastroenterology, 5, e45. https://doi.org/10.1038/ctg.2013.13.

StataCorp. (2011). Stata statistical software: Release 12. College Station: StataCorp LP.

Stichting Benchmark GGZ (2016). Position Paper: Benchmarken is beter worden door te vergelijken [Position paper: Benchmarking is becoming better by comparing]. Retrieved from https:/www.sbggz.nl/Over-SBG? contentitem $=\mathrm{b} 49041 \mathrm{~b} 8-\mathrm{bb} 96-4 \mathrm{~d} 2 \mathrm{a}-\mathrm{abc} 6-56 \mathrm{ac} 55 \mathrm{f} 3 \mathrm{ec} 25$ \& paragraph $=$ 14cc6e96-474e-4a3d-a365-b69077113168\#Position-Paper.

Stuart, E. A. (2010). Matching methods for causal inference: A review and a look forward. Statistical Science, 25, 1-21. https://doi.org/10. 1214/09-sts313.

Stuart, E. A., Cole, S. R., Bradshaw, C. P., \& Leaf, P. J. (2011). The use of propensity scores to assess the generalizability of results from randomized trials. Journal of the Royal Statistical Society: Series A (Statistics in Society), 174, 369-386. https://doi.org/10.1111/j. 1467-985x.2010.00673.x.

Sundell, K., Hansson, K., Löfholm, C. A., Olsson, T., Gustle, L. H., \& Kadesjö, C. (2008). The transportability of multisystemic therapy to Sweden: Short-term results from a randomized trial of conductdisordered youths. Journal of Family Psychology, 22, 550-560. https://doi.org/10.1037/a0012790.

Thoemmes, F. J., \& Kim, E. S. (2011). A systematic review of propensity score methods in the social sciences. Multivariate Behavioral
Research, 46, 90-118. https://doi.org/10.1080/00273171.2011. 540475.

van der Laan, A. M., Slotboom, A.-M., \& Stams, G. J. (2010). Wat werkt? Bijdrage aan het terugdringen van recidive [what works? Contribution to reducing recidivism]. In H. M. P. J. Koppen, M. Jelicic, \& J. W. Keijser (Eds.), Reizen met mijn rechter. Psychologie van het recht (pp. 987-1001). Deventer: Kluwer.

van der Stouwe, T., Asscher, J. J., Stams, G. J. J. M., Deković, M., \& van der Laan, P. H. (2014). The effectiveness of multisystemic therapy (MST): A meta-analysis. Clinical Psychology Review, 34, 468-481. https://doi.org/10.1016/j.cpr.2014.06.006.

Verhulst, F. C., \& van der Ende, J. (2001a). Gedragsvragenlijst voor kinderen van 6 tot 18 jaar [CBCL 6-18] [Child Behavior Checklist for children aged 6 to 18]. Rotterdam: Erasmus MC-Sophia Kinderziekenhuis.

Verhulst, F. C., \& van der Ende, J. (2001b). Zelf in te vullen vragenlijst voor 11-18 jarigen [YSR 11-18] [Youth Self Report for adolescents aged 11 to 18]. Rotterdam: Erasmus MC-Sophia Kinderziekenhuis.

Vermeulen, K. M., Jansen, D. E. M. C., Knorth, E. J., Buskens, E., \& Reijneveld, S. A. (2017). Cost-effectiveness of multisystemic therapy versus usual treatment for young people with antisocial problems. Criminal Behaviour and Mental Health, 27, 89-102. https:// doi.org/10.1002/cbm.1988.

Vermulst, A., Kroes, G., De Meyer, R., Nguyen, L., \& Veerman, J. W. (2012). Opvoedingsbelastingvragenlijst (OBVL). Handleiding [questionnaire on parenting stress. Manual]. Nijmegen: Praktikon.

West, S. G., Cham, H., Thoemmes, F. J., Renneberg, B., Schulze, J., \& Weiler, M. (2014). Propensity scores as a basis for equating groups: Basic principles and application in clinical treatment outcome research. Journal of Consulting \& Clinical Psychology, 82, 906919. https://doi.org/10.1037/a0036387.

Yirmiya, N. (2010). Editorial: Early prevention and intervention - The five W (and one H) questions. Journal of Child Psychology and Psychiatry, 51, 1297-1299. https://doi.org/10.1111/j.1469-7610. 2010.02344.x. 